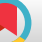

\title{
Quality of Work-life of Iranian Police Officers in the Year 2020: A Descriptive Study
}

\author{
Zeinab Tabanejad ${ }^{1}$, Fatemeh Oskouie (iD) ${ }^{2,}{ }^{*}$ and Abbas Ebadi (iD ${ }^{3,4}$ \\ ${ }^{1}$ Nursing Care Research Center, Iran University of Medical Sciences Trauma in Police Operations Research Center, Department of Health, Rescue and Treatment of Police \\ Force, Tehran, Iran \\ ${ }^{2}$ Nursing Care Research Center and School of Nursing and Midwifery, Iran University of Medical Sciences, Tehran, Iran \\ ${ }^{3}$ Behavioral Sciences Research Center, Life Style Institute, Baqiyatallah University of Medical Sciences, Tehran, Iran \\ ${ }^{4}$ Nursing Faculty, Baqiyatallah University of Medical Sciences, Tehran, Iran \\ "Corresponding author: Nursing Care Research Center, School of Nursing and Midwifery, Iran University of Medical Sciences, Tehran, Iran. Email: fatemehoskouie@gmail.com
}

Received 2020 October 13; Revised 2020 November 24; Accepted 2020 December 11.

\begin{abstract}
Background: Stressful workplace experiences of police officers predispose them to physical and psychological injuries and affect their quality of work-life (QWL).

objectives: Therefore, this study aimed to examine the QWL of Iranian police officers.

Methods: This descriptive cross-sectional study was conducted in 2020 on 200 police officers working in different job positions of the Iranian Police Organization. A convenience sampling method was used to recruit the participants from 12 police departments in five cities. The Police Quality of Work-life questionnaire (PQWLQ) was used for data collection. The measures of descriptive and inferential statistics (independent-samples t-test, one-way analysis of variance, and Pearson correlation coefficient) were used for data analysis.

Results: Of the 200 police officers, 87.5\% (175) were males, 68\% (136) had a bachelor's degree or higher, and their work experience ranged between five and 27 years. The QWL score of the study participants ranged from 24 to 120 with a mean ( \pm SD) of 63.20 ( \pm $18.40)$, and the majority of them (56\%) had a moderate QWL. Male police officers had a higher QWL $(67 \%)$ than female ones $(45 \%)(\mathrm{P}<$ $0.05)$.

Conclusions: The majority of the police officers who participated in this study had a moderate QWL. To increase the level of QWL among police officers, the Police authorities should plan appropriate strategies and programs.
\end{abstract}

Keywords: Quality of Work-life, Police, Iran

\section{Background}

The police officers have a high-risk, dynamic, and stressful job (1). Problems with dangerous missions, overseas duties (2), obligation to keep their physical fitness (3), sleep deprivation due to shift work (4), separation from the family, and performing non-combat tasks such as relief, peacekeeping, and other humanitarian activities are very onerous and cumbersome for police officers (5). Police officers also are at a high risk of job burnout due to repeated exposure to traumatic and stressful conditions (6). The continuation of these tensions will affect the quality of work-life (QWL) of police officers. However, organizational success (7) and sustainable improvement and productivity of an organization depend on effective human resource management, which, in turn, requires innovation, intelligence, and the ability to create a quality working life for employees (8).
In addition, recruiting and retaining qualified employees is a priority (9) because employees' turnover makes the organizations to expend for hiring and training new employees (10). Furthermore, the employees' reduced work conscience and weakened organizational commitment would increase the pressure on their colleagues and also lessen the organizations' social capital (11). However, it is believed that improving the employees' QWL would improve labor productivity and increase their organizational commitment and workplace attachment (12).

Quality of work-life is a subjective phenomenon that is affected by an employee's feelings and perceptions (13). Focusing on the improvement of QWL would increase the employees' contentment and satisfaction that consequently would result in various advantages for both employees and organizations (14). Studies have shown that organizations offering better QWL are more successful in hiring and re- 
taining their valuable workforce $(15,16)$.

Several studies have examined the QWL of nurses (17), employees with intellectual disability (18), teachers (19), hotel employees (20), and employees in mechanical manufacturing small and medium-sized enterprises (21). However, a few studies have been conducted on the police workforce despite their unique and stressful job. Assessing the QWL of police staff is the first step in planning appropriate strategies for improving their QWL.

\section{Objectives}

Thus, this study aimed to examine the QWL of Iranian police officers.

\section{Methods}

A descriptive cross-sectional study was conducted in 2020 in the Iranian Police Organization. The inclusion criteria were having at least five years of experience in the organization in various positions such as the police station, patrolman, border guard, etc. The exclusion criterion was an incomplete questionnaire. A convenience sampling method was used to recruit the participants from 12 police departments in five cities (Tehran, Kerman, Kermanshah, Mashhad, and Bandar-e-Abbas). A two-part instrument was used for data collection. The first part included items on participants' characteristics, and the second part was the Police Quality of Work-life questionnaire (PQWLQ) developed by Tabanejad et al. (22). The PQWLQ contains 24 items in two dimensions, namely organizational climate (10 items) and organizational support (14 items). Items cover different areas of the QWL and are responded to on a five-point Likert scale, as follows: 1: "never", 2: "rarely", 3: "occasionally", 4: "often", and 5: "always". Thus, its total score may range from 24 to 120, and a higher score indicates a higher QWL. For content validity, we asked 10 nursing experts. The ICC was $0.80,0.97$, and 0.93 for 'organizational climate", "organizational support", and the whole scale, respectively. The reliability of the questionnaire was also calculated through the internal consistency method, and Cronbach's alpha was 0.947 (22). The sample size obtained using the Krejcie and Morgan formula (23). To determine the level of QWL, the difference between the minimum and maximum scores was used. Then, the results (96) were divided by three and the resulting number with a minimum total score was considered as a low level of QWL (56). By adding again, the moderate level was created, and finally by adding the number 32 again, a high level of QWL was obtained.

The first researcher referred to each participant, invited him/her to the study, and if agreed, handed in the study instrument and trained on how to answer in a private environment. The participant returned the complete instrument to the researcher at the next visit. The data were analyzed with the SPSS software (V. 16.0). The measures of descriptive and inferential statistics (independent-samples $t$-test, one-way analysis of variance, and Pearson correlation coefficient) were used for data analysis (P-value $<0.05$ ).

\section{Results}

A total of 220 questionnaires were distributed and finally, 200 fully completed questionnaires were returned (response rate $=91 \%$ ). Of the 200 police officers who completed the study, $87.5 \%$ were males, and $68 \%$ had a bachelor's degree or higher. The age range of the participants was between 24 and 65 years and their work experience ranged between five and 27 years (Table 1). The mean QWL score of the participants was $63.20 \pm 18.40$, and a majority of them (56\%) had a moderate level of QWL. Male police officers had a higher QWL (67\%) than female ones (45\%). The QWL was correlated with organizational climate $(\mathrm{r}=0.558)$ and organizational support $(\mathrm{r}=0.525)$. Tables 2 to 4 show the mean QWL of police officers by gender, marital status, and education level. Intra-correlation between scores of the subscales and the whole scale is shown in Table 5.

\begin{tabular}{|cc|}
\hline Table 1. Characteristics of the Study Participants & No. $(\%)$ \\
\hline Characteristics & \\
\hline Gender & $175(87.50)$ \\
\hline Male & $25(12.50)$ \\
\hline Female & \\
\hline Age & $75(37.50)$ \\
\hline $24-30$ & $112(56.00)$ \\
\hline $31-50$ & $13(6.50)$ \\
\hline 51 - 65 & $155(77.50)$ \\
\hline Education & $6(3.00)$ \\
\hline Under diploma & $4(2.00)$ \\
\hline Diploma & $32(16.00)$ \\
\hline Associate degree & $28(14.00)$ \\
\hline Bachelor's degree & $114(57.00)$ \\
\hline Master's degree or higher & $22(11.00)$ \\
\hline Work experience & $39(19.50)$ \\
\hline 5 - 10 & \\
\hline 11- 20 & \\
\hline
\end{tabular}




\begin{tabular}{|c|c|c|c|c|}
\hline Factors & Frequency & Mean \pm SD & $t$ Statistics & $\mathbf{P}$ \\
\hline Organizational climate & & & -0.367 & 0.714 \\
\hline Male & 169 & $70.91 \pm 18.43$ & & \\
\hline Female & 31 & $69.62 \pm 20.70$ & & \\
\hline Male & 169 & $53.63 \pm 20.85$ & & \\
\hline Female & 31 & $51.67 \pm 22.95$ & & \\
\hline \multicolumn{5}{|l|}{ Total } \\
\hline Male & 169 & $62.47 \pm 19.97$ & -0.561 & 0.575 \\
\hline Female & 31 & $60.51 \pm 17.82$ & & \\
\hline Factors & Frequency & Mean \pm SD & F Statistics & $\mathbf{P}$ \\
\hline Organizational climate & & & 0.646 & 0.586 \\
\hline Single & 51 & $72.35 \pm 15.77$ & & \\
\hline Married & 143 & $69.86 \pm 19.31$ & & \\
\hline Divorced & 4 & $78.50 \pm 14.20$ & & \\
\hline Widowed & 2 & $64.16 \pm 42.59$ & & \\
\hline Total & 200 & $70.54 \pm 18.79$ & & \\
\hline Organizational support & & & 4.709 & 0.003 \\
\hline Single & 51 & $59.83 \pm 22.66$ & & \\
\hline Divorced & 4 & $69.64 \pm 18.55$ & & \\
\hline Widowed & 2 & $82.14 \pm 5.05$ & & \\
\hline Total & 200 & $53.41 \pm 21.11$ & & \\
\hline
\end{tabular}

\section{Discussion}

This study was conducted to investigate the QWL of Iranian police officers. The mean QWL score of police officers was at a moderate level. This finding was consistent with the findings of an earlier study on a sample of military state police officers in Brazil (24) and the police station in Bangkok metropolis (25). Also, Rostami et al. (26) stated that QWL was at an intermediate level. However, Punluekdej (25) considered that the overall QWL of police officers at the police station in Bangkok metropolis was at a high level.

Studies in India, Nigeria, and Sweden also reported that police staff was not satisfied with their QWL and wellness (27-29), and they were under pressure and experienced emotional exhaustion (1). Although no further studies are available on the QWL of police officers, two studies in Iran have reported that clinical nurses have moderate (30) to favorable QWL (31). However, high levels of QWL are necessary to maintain employees in organizations and reflect the type of relationships between employees and their work environment (32). The moderate level of QWL in police officers necessitates further studies to identify factors affecting police officers' QWL.

In the present study, the QWL was correlated with organizational climate (including socio-psychological balance, self-actualization, etc.) and organizational support (including human resource development, positive management, etc.). The study on 200 police officers by Rani et al. (33) also showed that the QWL and its dimensions were significantly associated with psychological wellbeing (i.e., experiencing autonomy, control over the environment, personal growth, positive relations with others, purpose in life, and self-acceptance), which resulted in life satisfaction.

Regarding the impact of organizational support, a study of 630 Indian police officers has also addressed the QWL in the five areas of the physical aspect, welfare facil- 


\begin{tabular}{|c|c|c|c|c|}
\hline Factors & Frequency & Mean \pm SD & F Statistics & $\mathbf{P}$ \\
\hline Organizational climate & & & 0.703 & 0.590 \\
\hline Under diploma & 4 & $65.62 \pm 16.75$ & & \\
\hline High school diploma & 32 & $71.48 \pm 18.71$ & & \\
\hline Bachelor's degree & 101 & $70.70 \pm 17.36$ & & \\
\hline Master's degree or higher & 32 & $74.68 \pm 20.07$ & & \\
\hline Total & 200 & $70.82 \pm 18.44$ & & \\
\hline Organizational support & & & 0.749 & 0.560 \\
\hline Under diploma & 4 & $57.73 \pm 27.74$ & & \\
\hline High school diploma & 32 & $51.87 \pm 17.45$ & & \\
\hline associate degree & 31 & $52.02 \pm 21.83$ & & \\
\hline Bachelor's degree & 101 & $52.73 \pm 21.62$ & & \\
\hline Master's degree or higher & 32 & $59.21 \pm 21.84$ & & \\
\hline Total & 200 & $53.39 \pm 21.00$ & & \\
\hline Total & & & 0.973 & 0.423 \\
\hline Under diploma & 4 & $60.95 \pm 23.93$ & & \\
\hline High school diploma & 32 & $61.67 \pm 16.71$ & & \\
\hline Associate degree & 31 & $59.89 \pm 19.43$ & & \\
\hline Bachelor's degree & 101 & $61.79 \pm 17.61$ & & \\
\hline Master's degree and higher & 32 & $67.91 \pm 18.19$ & & \\
\hline
\end{tabular}

\begin{tabular}{lcc}
\hline \multicolumn{1}{l}{ Table 5. Intra-correlation Between Scores for Subscales and the Whole Scale } \\
\hline Scale (Subscale) & ICC & PValue \\
\hline Organizational climate & 0.80 & 0.0001 \\
Organizational support & 0.97 & 0.0001 \\
Total & 0.93 & 0.0001 \\
\hline
\end{tabular}

ities, spirituality, economic condition, and emotional aspect, and reported that police officers were not satisfied with their QWL. Moreover, the police department did not adequately train them on stress management, communication skills, team building, and attitudinal change and also did not make adequate initiatives to enhance their QWL (34). Evidence shows a clear relationship between positive and negative work experiences and the psychological well-being or perceived QWL of police officers (35). A study also concluded that the QWL can affect job satisfaction that ultimately would influence the employees' organizational performance either positively or negatively (36). Concerning organizational climate factors, Lee et al. (cited in Piip) also concluded that improving the employ- ees' QWL would not only improve the organization's productivity but also enhance the employee's personal efficiency and self-actualization (37). A focus on improving the employees' QWL will increase their job satisfaction and can bring benefits to employees and organizations (37). Balaji et al. (38) also reported that improving the QWL can facilitate a more humane work environment in which both the employees' basic needs and high-level needs of continuous growth and self-efficacy will be covered. Maintaining a favorable QWL is possible only when employees' job expectations are matched with the needs of their personal life and they are satisfied with their work and worklife (38). Some studies have also shown that the QWL can increase the employees' organizational commitment, job satisfaction (39, 40), emotional commitment (39), job performance, and life satisfaction (14) while it significantly decreases intention to leave, job burnout (39), and job stress (41). However, in a study on military state police officers, no association was found between the QWL and employees' self-efficacy (24).

According to the findings of this study, the mean QWL score was higher in male police officers than in their fe- 
male counterparts. This finding can be attributable to the fact that the number of male police officers was considerably higher in our study. Nonetheless, the higher QWL of male police officers in the present study is consistent with some of the former studies in Nigeria (28) and Indonesia (42).

Human resources play an important role in the success of any organization. Most of the problems in organizations are related to human and social relations rather than physical or technical aspects. A good QWL not only attracts new talented people but also strengthens and retains the existing talented workforce and causes them to enjoy their profession. Conversely, those how are dissatisfied with their job experience and feel lower QWL have weaker performance in their job. Good managers try to look after the organization's employees as the "assets of the organization" and improve their QWL. They believe that people perform better if they are satisfied with their job, take part in making job-related decisions, and experience a better QWL (43).

\subsection{Study Limitations}

The high workload of the police and their preoccupation might have interfered with their accuracy in completing the questionnaire. Furthermore, although the researcher tried to assure the participants about the confidentiality of the information, a worry about the consequences of their responses may have affected their answers. Furthermore, we used a self-report questionnaire, and the items in such instruments may induce some bias in the participants' answers. Future studies are suggested using interviews and observations to gather more reliable data. Furthermore, the simultaneous assessment of QWL, job burnout, job satisfaction, and their interrelationships are suggested.

\subsection{Conclusions}

The Iran Police Organization is one of the dynamic and active organizations with a key role in the security and order of society. Therefore, it needs employees with high levels of job commitment who are satisfied with their QWL. Otherwise, they might not do well in their sensitive duties and missions. The police officers studied in this study had a QWL at a moderate level. Therefore, more attention should be paid to recognize the influential factors and create the necessary modifications to enhance their QWL.

\section{Acknowledgments}

This article was part of a doctoral dissertation supported by the Nursing Research Center of the School of Nursing of Iran University of Medical Sciences (IR.IUMS.REC code 1396.9421199006). The authors are thankful to the Iran University of Medical Sciences and all police officers who participated in this study.

\section{Footnotes}

Authors' Contribution: Fatemeh Oskouie and Zeinab Tabanejad were responsible for the study notion and design. Zeinab Tabanejad gathered the data. Abbas Ebadi performed the data analysis. Fatemeh Oskouie, Zeinab Tabanejad, and Abbas Ebadi drafted and revised the manuscript.

Conflict of Interests: The authors declare that there is no conflict of interest regarding the publication of this article.

Ethical Approval: This study was approved by the Ethics Committee of the Iran University of Medical Sciences, Tehran, Iran (code: IR.IUMS.REC.1396.9421199006).

Funding/Support: This research was financially supported by the Nursing Care Research Center of Iran University of Medical Sciences.

Informed Consent: At the beginning of the study, participants were informed of the study objectives and methods, voluntary participation, and confidential data management, and verbal informed consent was obtained from each of them.

\section{References}

1. Padyab M, Backteman-Erlanson S, Brulin C. Burnout, Coping, Stress of Conscience and Psychosocial Work Environment among Patrolling Police Officers. J Police Crim Psychol. 2016;31(4):229-37. doi: 10.1007/s11896-015-9189-y.

2. Oznur T, Akarsu S, Erdem M, Durusu M, Toygar M, Poyrazoglu Y, et al. Psychiatric Symptoms and Quality of Life in Military Personnel Deployed Abroad. Isr J Psychiatry Relat Sci. 2015;52(3):60-4. [PubMed: 27357555].

3. Adams AL, Shi J, Takayanagi M, Dell RM, Funahashi TT, Jacobsen SJ. Tenyear hip fracture incidence rate trends in a large California population, 1997-2006. Osteoporos Int. 2013;24(1):373-6. doi: 10.1007/s00198012-1938-5. [PubMed: 22349963]

4. Taylor MK, Hilton SM, Campbell JS, Beckerley SE, Shobe KK, Drummond SP, et al. Prevalence and mental health correlates of sleep disruption among military members serving in a combat zone. Mil Med. 2014;179(7):744-51. doi: 10.7205/MILMED-D-13-00551. [PubMed: 25003859].

5. Riggs SA, Riggs DS. Risk and resilience in military families experiencing deployment: the role of the family attachment network.JFam Psychol. 2011;25(5):675-87. doi: 10.1037/a0025286. [PubMed: 21875201].

6. Backteman-Erlanson S. Burnout, work, stress of conscience and coping among female and male patrolling police officers. Umea universitet; 2013.

7. Hermawati A, Mas N. Mediation effect of quality of worklife, job involvement, and organizational citizenship behavior in relationship between transglobal leadership to employee performance. Int J Law Manag. 2017. 
8. Farsi Z, Habibi H, Lashkari MH. Relationship Between Productivity and Burnout in Nurses of Military Hospitals in Tehran.J Arch Mil Med. 2014;2(1). doi: 10.5812/jamm.16276.

9. Sirin M, Sokmen SM. Quality of nursing work life scale: the psychometric evaluation of the Turkish version. Int J Caring Sci. 2015;8(3):543.

10. Sitterding MC, Broome ME, Everett LQ, Ebright P. Understanding situation awareness in nursing work: a hybrid concept analysis. ANS Adv Nurs Sci. 2012;35(1):77-92. doi: 10.1097/ANS.0b013e3182450158. [PubMed: 22293612].

11. Lee YW, Dai YT, McCreary LL. Quality of work life as a predictor of nurses' intention to leave units, organisations and the profession. J Nurs Manag. 2015;23(4):521-31. doi: 10.1111/jonm.12166. [PubMed: 24238014].

12. Daubermann DC, Tonete VLP. Quality of work life of nurses in primary health care. Acta Paul Enferm. 2012;25(2):277-83.

13. Lee YW, Dai YT, Park CG, McCreary LL. Predicting quality of work life on nurses' intention to leave. J Nurs Scholarsh. 2013;45(2):160-8. doi: 10.1111/jnu.12017. [PubMed: 23462044]

14. Dhamija P, Gupta S, Bag S. Measuring of job satisfaction: the use of quality of work life factors. Benchmark Int J. 2019.

15. Surienty L, Ramayah T, Lo M, Tarmizi AN. Quality of Work Life and Turnover Intention: A Partial Least Square (PLS) Approach. Soc Indic Res. 2013;119(1):405-20. doi: 10.1007/s11205-013-0486-5.

16. Akter N, Akkadechanunt T, Chontawan R, Klunklin A. Factors predicting quality of work life among nurses in tertiary-level hospitals, Bangladesh. Int Nurs Rev. 2018;65(2):182-9. doi: 10.1111/inr.12401. [PubMed: 29105085].

17. Brooks BA, Anderson MA. Defining quality of nursing work life. Nurs Econ. 2005;23(6):319-26. 279. [PubMed: 16459904].

18. Kocman A, Weber G. Job Satisfaction, Quality of Work Life and Work Motivation in Employees with Intellectual Disability: A Systematic Review. J Appl Res Intellect Disabil. 2018;31(1):1-22. doi: 10.1111/jar.12319. [PubMed: 28000421].

19. Yang D, Lu J. Rural Teachers' Quality of Work Life (QWL) in China: The Case of Shanxi Province. Acad J Interdiscip Stud. 2014. doi: 10.5901/ajis.2014.v3n4p39.

20. Kim T, Karatepe OM, Lee G, Lee S, Hur K, Xijing C. Does hotel employees' quality of work life mediate the effect of psychological capital on job outcomes? Int J Contemp Hospitality Manag. 2017;29(6):1638-57. doi: 10.1108/ijchm-04-2016-0224.

21. Swamy DR, Nanjundeswaraswamy TS, Rashmi S. Quality of work life: scale development and validation. Int J Caring Sci. 2015;8(2):281.

22. Tabanejad Z, Oskouie F, Ebadi A, Mesri M. Development and psychometric evaluation of the police quality of work-Life questionnaire. Nurs Midwifery Stud. 2020;9(3).doi:10.4103/nms.nms_14_19.

23. Krejcie RV, Morgan DW. Determining Sample Size for Research Activities. Educ Psychol Measure. 2016;30(3):607-10. doi: 10.1177/001316447003000308.

24. Coelho E, Antloga C, Maia M, Takaki K. Autoeficácia e Qualidade de Vida no Trabalho: um estudo com policiais militares. Psicologia. 2016;32(spe). doi: 10.1590/0102-3772e32ne220.

25. Punluekdej T. Quality of work life of police officers: A case study of a police station in bangkok metropolis. International Academic Multidisciplinary Research Conference in Switzerland 2020. 2020. p. 252-61

26. Rostami H, Fathi A, Azmodeh M, Ebrahimzadeh Asl E. Relationship between Job Burnout, Job Motivation and Resilience with Quality of Work Life of Treatment Staff in one of the Armed Forces Hospitals in 2018. J Police Med. 2019;9(1):35-42.

27. Bhagyalaxmi. M. D. I. P. Quality of working life of women police. Paripex-Indian J Res. 2016;5(6):203-5.

28. Ogungbamila A, Idemudia ES. Gender differences in quality of work life of police personnel in two selected states in South-West, Nigeria. Gender Behav. 2016;14(1):7019-27.

29. Lee YW, Dai YT, McCreary LL, Yao G, Brooks BA. Psychometric properties of the Chinese-version Quality of Nursing Work Life Scale. Nurs Health Sci. 2014;16(3):298-306. doi: 10.1111/nhs.12099. [PubMed: 24635946].

30. Abadi F, Abadi F. Survey factors affecting of quality of work life in the clinical nurses. Nurs Midwifery Stud. 2019;16(11):832-40.

31. Hesam M, Asayesh H, Roohi G, Shariati A, Nasiry H. Assessing the relationship between nurses' quality of work life and their intention to leave the nursing profession. Q J Nurs Manag. 2012;1(3):28-36.

32. Mohammadi M, Mozaffari N, Dadkhah B, Etebari Asl F, Etebari Asl Z Study of work-related quality of life of nurses in Ardabil Province Hospitals. J Health Care. 2017;19(3):108-16.

33. Rani R, Kumar N, Rastogi R, Garg P. Quality of work life: Predictor of psychological wellbeing of police employees. Indian J Positive Psychol. 2012;3(4):356.

34. Lele DP. Quality of work-life of police constables with special reference to wellness. J Bus Manag. 2014;16(11):46-51. doi: 10.9790/487X161144651.

35. Easton S, Van Laar D, Marlow-Vardy R. Quality of working life and the police. Management. 2013;3(3):135-41.

36. Srivastava S, Kanpur R. A Study On Quality Of Work Life: Key Elements \& It's Implications. IOSR J Bus Manag. 2014;16(3):54-9. doi: $10.9790 / 487 \mathrm{X}-16315459$.

37. Piip J. Mentoring for Career Development: Organisational Approaches to Engage and Retain Employees. Sustainable Rail Transport. 2019. p. 269-87. doi:10.1007/978-3-319-78544-8_15.

38. Balaji P, Behera S, Kumar A. Dimensionality and Antecedents of Quality of Work Life. Sumedha J Manag. 2018;7(3):22-8.

39. Akar H. The Relationships between Quality of Work Life, School Alienation, Burnout, Affective Commitment and Organizational Citizenship: A Study on Teachers. Eur J Educ Res. 2018;7(2). doi: 10.12973/eujer.7.2.169.

40. Aruldoss A, Kowalski KB, Parayitam S. The relationship between quality of work life and work life balancemediating role of job stress, job satisfaction and job commitment: evidence from India. J Adv Manag Res. 2020;ahead-of-print(ahead-of-print). doi: 10.1108/jamr-05-20200082.

41. Hong K, Tan K, Bujang S. Relationships between work life quality of teachers with work commitment, stress and satisfaction: A study In Kuching, Sarawak, Malaysia. J Teknol. 2010;52(1):1-15.

42. Ramly M, Asmawi M, Aryanto T. The Effect of Emotional Intelligence, Quality of Work Life, and Stress on Job Satisfaction and Turnover Intention Among The Employees. Int J Sci Res Manag. 2018;6(5). doi: 10.18535/ijsrm/v6i5.em08.

43. Kaur K. Impact of demographic variables on quality of work lifeA study of private universities in Punjab. ZENITH Int J Multidisc Res. 2018;8(9):57-73. 